LECTURE 1

\title{
INTRODUCTION: THE HISTORY OF BEHAVIORAL FINANCE AND THE IMPETUS FOR ITS EMERGENCE
}

\begin{tabular}{|l|}
\hline \multicolumn{1}{|c|}{ Agenda } \\
$>$ What is Behavioral Finance? \\
$>$ The Topics we'll Cover in the Course \\
$>$ The History of Behavioral Finance and the Impetus for Its Rise \\
$>$ Review of the Efficient Market Hypothesis (EMH) and the \\
Capital Asset Pricing Model (CAPM) \\
$>$ Profitability Measures \\
$>$ Market Inefficiencies/Anomalies \\
$>$ CAPM Extensions and Multi-Factor Asset Pricing Theories
\end{tabular}

In this lecture, we will first explain what is the area of behavioral finance and we will then briefly describe the main topics to be covered in this course. Subsequently, we will discuss why and how this new area of finance evolved over time. To better understand the evolution of behavioral finance and its contribution to the more general field of finance, we will review the concepts of market efficiency, the capital asset pricing model (CAPM) and some more advanced pricing theories. I will also give a short review of some well-known stock market anomalies. 


\section{What is Behavioral Finance?}

Behavioral finance is the area in finance that studies the intersection of finance and psychology and explores the effect of cognitive biases on the behavior of market participants, on the functioning of capital markets and on the prices of capital and other assets.

Behavioral finance is the fastest growing area in academic research in finance. It started its meteoric rise circa the mid-1980s and it is by now an important part of finance in investments and in corporate finance. Finance is a dynamic area and it has developed many sub-areas over time either because of new theoretical findings, market developments and legislation. For example, the market for options grew in the 1970s, in part, because of the theoretical advances in the pricing of options. Likewise, the area of behavioral finance was developed as a reaction to theoretical findings in psychology and to evidence from financial markets that did not sit well with market efficiency. These findings prompted the fusion of insights from the two distinct fields to create behavioral finance. The new area, as we shall see during this course, contributes considerably to the understanding of the behavior of capital markets and capital markets participants. Behavioral finance has many applications that help individuals, corporations, analysts, professional investors and legislators to make better financial decisions and to improve the functioning of capital markets.

Since behavioral finance explores biases, it may seem that it mainly points at activities that decision makers need to avoid. However, revealing the cognitive biases of decision makers and becoming aware of flaws in their judgments, allows us to find ways to overcome these biases and to design policies to improve financial decision making and the functioning of capital markets. Authors such as Ariely (2008, 2010), Kahneman (2011), and Thaler and Sunstein (2009), popularized behavioral finance by making the concepts of this area more accessible to academics, analysts, professional investors and laypeople. 


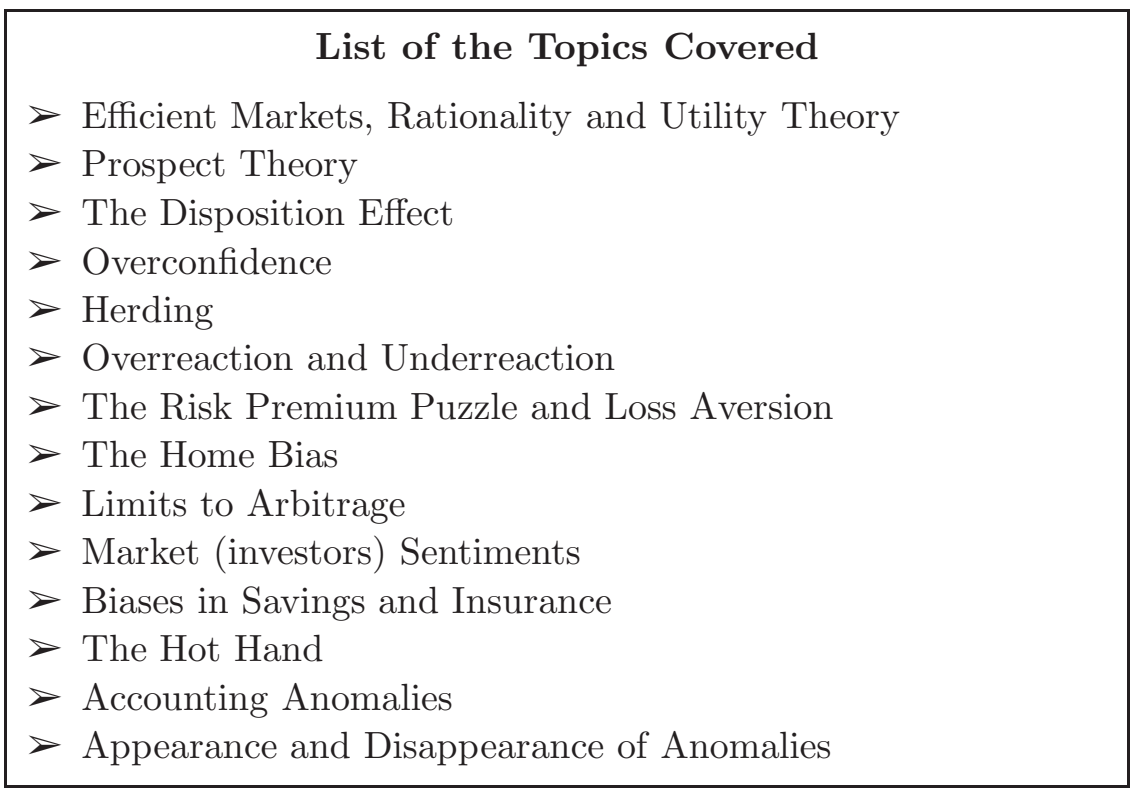

Although the list of topics is extensive, it does not exhaust all topics in behavioral finance. While this area is relatively new, it has become quite large, and covering all topics is not only prohibitive but also counterproductive. Instead, this course will cover the most important theories and issues. We will emphasize the broad significance of the psychological and financial concepts rather than go in detail over their statistical and theoretical fine points.

\section{The History and Evolution of Behavioral Finance and the Impetus for Its Emergence}

It is hard to pinpoint when exactly behavioral finance started, but its origins however can be traced to sometime in the mid-to late 1980s. During the 1970s and 1980s, there was a growing dissatisfaction and frustration in finance from the failure to deal with findings (anomalies) that did not match the Efficient Market Hypothesis (EMH) and 
the assumption of investors rationality. These anomalies in addition to numerous financial crises and well-documented bubbles (a bubble is an occurrence where the prices of assets rise without apparent reasons and eventually crash) posed a major challenge to main stream finance that extolled the EMH and investors rationality. Examples for bubbles and crashes that preceded the birth of behavioral finance abound, but we will mention only the following: The Dutch Tulip Mania aka "Tulipomania" of 1634-1637, the Stock Market Crash of 1929, the Mississippi Bubble (1716-1720), the Florida Real Estate Bubble of the 1920s, the savings and loan crisis of the 1980s and Black Monday — the Stock Market Crash of 1987 (which reinforced behavioral finance in its early days).

For brevity, we will go over just few of these phenomena: Tulips, because of their rarity and beauty became favorites of the Dutch high society and speculators in the 17th century, causing their prices to soar to "insanely" high levels. At some point, according to British journalist Charles Mackay (cited in Thompson, 2007), 12 acres of land were offered during that period for a Semper Augustus bulb. Some tulip bulb prices became worth the equivalent of tens of thousands of dollars (in current values) and many Dutch tulip speculators became fantastically wealthy. However, when prices fell to their "sane" levels many investors were ruined and Dutch commerce suffered a severe shock throwing the Netherlands into a mild economic depression that lasted for many years.

Black Monday refers to Monday, October 19, 1987, when stock markets around the world crashed. The Dow Jones Industrial Average (DJIA) fell by $22.61 \%$, the largest one day percentage fall of the DJIA. There were no apparent reasons for such a crash, and despite the efforts of many researchers to explain this event, no explanation prevailed. Following the stock market crash, a group of 33 eminent economists from various nations met in Washington, D.C and collectively predicted that "the next few years could be the most troubled since the 1930s" (see The New York Times, 1987). However, the economy was barely affected and growth actually increased throughout 1987 and 1988, with the DJIA regaining its pre-crash closing high of 2,722 points in early 1989 . 
The failure to explain phenomena, such as those described above, implied that either markets were not efficient or that theory was lacking or both, and that people could systematically behave irrationally and markets inexplicably. New pricing theories were offered, but also these theories could not explain all anomalies.

While in finance researchers were struggling to explain anomalies via traditional economics, in the psychological sphere, important new strides were made. Kahneman and Tversky published their paper on prospect theory in 1979. This theory together with the many cognitive biases which Kahneman and Tversky, and their many colleagues and students have discovered, started to grab the attention and approval of many financial economists in the early 1980s. One of the main attractions of their theory was that they were able to identify some large classes of cognitive biases and showed the prevalence of these classes of biases. The world of psychological and cognitive biases, which until then seemed chaotic, suddenly started to make sense.

The fusion of these two developments is how behavioral finance was born. It was not until the mid-1980s and early 1990s that main stream finance journals started to publish papers by leading financial economists that favorably viewed behavioral finance concepts and that were critical of the EMH. Acknowledgment of phenomena that previously seemed heretic by mainstream finance such as "market inefficiency", "limits to arbitrage", "overreaction" and "market sentiment" became acceptable in the early 1990s.

The emergence of behavioral finance did not, of course, eliminate bubbles and anomalies that continued to appear also in later periods, nor could behavioral finance fully explain these phenomena. Hence, behavioral finance's work is not yet done.

On the persistence of anomalies even beyond the 1980's, we will talk in Lecture 17. As for later days' bubbles (we mentioned earlier just pre behavioral finance ones), the dot-com bubble of the period 1995-2001 and the sub-prime crisis of 2007-2009 are worth mentioning here. During the early days of the dot-com bubble stock markets in many countries rose rapidly mainly due to the growth in values of technology firms. During that period many new firms were 
established with fantastically high prices even though they could not provide credible financial evidence or promise for future growth that would warrant such prices. Adding the suffix "com" or a prefix "e" to the firm's name would give the firm a "tech" aura and would add to its market value. Consequently, the average P/E of NASDAQ firms reached 200. The party started to crash in the late 1990s and early 2000s, as many firms that saw a spectacular growth, such as pets.com and Webvan, went bankrupt and many others fell considerably (for example, Cisco's price per share fell by $86 \%$ and Amazon's fell from $\$ 107$ to $\$ 7$, it rebounded eventually and reached $\$ 768.7$ on December 12, 2016).

The sub-prime crisis refers to the sub-prime mortgage market collapse that caused a major banking crisis in the US and worldwide during 2007-2009. One of the triggers for this crisis was the bursting of the housing bubble, a sharp decline in housing prices after a long period where they steadily rose. The fall in prices led to a great number of mortgage delinquencies and foreclosures and the devaluation and default of housing-related securities such as mortgagebacked securities (MBS) and collateralized debt obligations (CDO), which were central in the financing of household debt. These instruments seemed to offer attractive rates of return, but these returns were specious since they overlooked the CDOs lower credit quality. Ultimately, these defaults caused the collapse of several major financial institutions in 2008 (e.g., Lehman Brothers) and caused a major economic crisis. This crisis is beautifully described in Michael Lewis' (2010), book: "The Big Short: Inside the Doomsday Machine" and the motion picture, "The Big Short" based on it that appeared in 2015 .

\section{Review of Market Efficiency and the Capital Asset Pricing Model (CAPM)}

To explain the shortcomings of traditional finance that paved the way for the emergence of behavioral finance, we will start the course with a review of the Efficient Market Hypothesis (EMH).

Markets are considered efficient if the prices of assets reflect all information (see, e.g., Berk and DeMarzo, 2007). 
There are three forms of market efficiency: weak efficiency, semi strong efficiency and strong efficiency. According to the first form of efficiency, current prices reflect all information provided by past prices, semi-strong efficiency means current prices reflect all published information (past prices and other public information), and strong form efficiency means prices reflect all information (including also insiders' information).

The EMH says that markets are by and large informationally wellfunctioning. The belief in this hypothesis has been the leading theme in mainstream financial theory and still is quite dominant (this is evident in almost any text book in introduction to finance, see, e.g., Brick, 2017, Berk and DeMarzo, 2007). Behavioral financeon the other hand, contends that the deviations from this hypothesis are significant and cannot be dismissed as mere peculiarities.

\section{Efficiency Criteria}

Markets are considered efficient if it is impossible to make abovenormal profits, based on the available information. Thus, to make this definition concrete, normal profits must be described. "Normal" profits are defined as those ascribed by some pricing theory (say, the CAPM; see, e.g., Berk and DeMarzo, 2007). According to the CAPM, the firm's total risk can be divided into two parts: the risk due to the firm's correlation with the market (the systematic risk, or "beta") and its idiosyncratic risk which is firm-specific. The CAPM then argues that in equilibrium, only the firm's "beta" affects its expected returns. The idiosyncratic risks are not rewarded with a risk premium since investors can diversify them away. The normal returns, or expected returns, according to the CAPM are shown below:

$$
\begin{gathered}
\text { The CAPM } \\
E\left[R_{i}\right]=R_{f}+\beta_{i}\left[E\left(R_{m}\right)-R_{f}\right]
\end{gathered}
$$

where:

$E\left[R_{i}\right]$ is the expected return on the stock of firm $i$, $E\left(R_{\mathrm{m}}\right)$ is the expected return on the market, 


\section{(Continued)}

$R_{f}$ is the risk free interest rate,

$\beta_{i}$ is firm $i$ 's measure of systematic risk, $E\left(R_{\mathrm{m}}\right)-R_{f}$ is the market risk premium.

We then say that there are inefficiencies if the returns on a stock are systematically higher than those predicted by the above formula for $E\left[R_{i}\right]$. We would also argue against efficiency when there are arbitrage opportunities, and when we observe behavior conflicting with well-accepted axioms or rationality, the correct way of calculating probabilities or with common sense.

Mispricing can exist because of limits of arbitrage. If arbitrage (the simultaneous purchase and sale of the same, or essentially similar securities in two different markets for advantageously different prices) opportunities were not limited, then the astute arbitrageurs would pounce on the underpriced securities buying such assets, possibly financing them by selling overpriced (or even correctly priced) assets, thus making above-normal profits.

\section{Profitability Measures}

In addition to normal profits defined by the CAPM, one can find some other profitability measures that are popular with practitioners and academics alike, where earning returns above them, and could constitute evidence against efficiency.

\section{Non Risk Adjusted Measures}

$$
R_{i}-R_{F}
$$

This measure is the "plain" risk premium, that is the return on asset $i$ above the risk-free rate. It is too elementary since it disregards the firm's riskiness. 


\section{Risk Adjusted Measures}

Lintner's ratio: $\left(R_{i}-R_{f}\right) / \beta_{i}$

Lintner's ratio measures the risk premium of the asset, $R_{i}-R_{F}$, relative to its systematic risk. It is appropriate for evaluating the performance of well-diversified portfolios.

\section{Sharpe Ratio: $\left(R_{i}-R_{f}\right) / \sigma_{i}$}

Sharpe's ratio measures the risk premium relative to the total risk of the asset $\sigma_{i}$. Since this measure is defined over total risk, it is better suited for the evaluation of non-diversified portfolios.

\section{Jensen's $\alpha$}

Jensen's $\alpha$ of a security (or its alpha) is another measure of its profitability. It is defined as the estimate of the intercept in the following regression:

$$
R_{i t}-R_{f t}=\alpha+\beta_{i}\left[R_{m t}-R_{f t}\right]
$$

In the above formula, we added a time index $t$ to the already defined variables: $R_{i}, R_{m}$ and $R_{f}$. In this regression, $R_{i}-R_{f}$ is the dependent variable, and $R_{m}-R_{f}$, the market risk premium, is the independent (explanatory) variable.

The logic behind this measure is the following: According to the CAPM,

$$
E\left[R_{i}\right]=R_{f}+\beta_{i}\left[E\left(R_{m}\right)-R_{f}\right]
$$

This can be rewritten as

$$
R_{i}=R_{f}+\beta_{i}\left[R_{m}-R_{f}\right]+\text { Errors, }
$$

Or, by subtracting $R_{f}$ from both sides, as

$$
R_{i}-R_{f}=0+\beta_{i}\left[R_{m}-R_{f}\right]+\text { Errors }
$$

Accordingly, if the profits are "normal" and we run the regression,

$$
R_{i t}-R_{f t}=\alpha+\beta_{i}\left[R_{m t}-R_{f t}\right]
$$


the estimate of $\alpha$ should be zero (more precisely, not significantly different from zero). A positive (negative) $\alpha$ indicates that asset $i$ earned above (below) normal profits. Assuming the current situation continues, above normal profits could be made by buying the asset (going long) if the alpha is positive and by selling it short if the alpha is negative.

\section{Market Inefficiencies/Anomalies}

Consistent market inefficiencies are situations where, contrary to market efficiency, investors could make above-normal profits, and hence are dubbed anomalies. We will go over market anomalies in greater detail later in the course. For now, we will mention just a few: The weekend effect, the January effect, size anomalies, P/E anomalies, momentum anomalies.

During the 1960s and 1970s, many scholars and practitioners found that above-normal profits could be made based on the above factors. For example, according to the weekend effect returns on Mondays are lower than in other days of the week. Since this is known, why don't arbitrageurs devise strategies of buying on Mondays and selling on other days and make easy profits. The debates around this effect usually ran along two lines: first, whether or not the effect is true or spurious (just a statistical artifact), and second, if the effect is genuine, why does it persist? The January effect refers to the phenomenon where many (mostly small) firms earn above-normal profits in January. According to the size anomaly, firms earned returns above those justified by their betas if they were small. Again, if this is a fact (and apparently known to all), then one could easily make above-normal profits by buying small firms prior to January. Their prices will then rise and their expected returns will fall until equilibrium is reached. Similar findings were discovered about the other above-mentioned factors. Observations of stocks that exhibited extreme $\mathrm{P} / \mathrm{E}$ ratios or prolonged periods of rise in prices (momentum) provided investment strategies yielding above-normal returns. 
In addition to the above anomalies, there developed in the 1960s and 1970s a whole industry of research examining the validity of the $\mathrm{EMH}$ in its semi-strong sense by using the methodology of event studies. These studies examined how asset returns react to public information such as earnings and dividend announcements, corporate announcements, corporate events, analysts' newsletters, Wall Street Journal articles, etc. EMH adherents used these methods to claim that markets are efficient as stock returns behave as expected according to theory, while their opponents argued the opposite (see, e.g., Bodie et al. 2013). Michael Jensen who used to be one of the more influential academics arguing for the EMH conceded in 1978: "taken individually many scattered pieces of evidence on the reaction of stock prices to earnings announcements which are inconsistent with the [Efficient Market] theory don't amount to much. Yet viewed as a whole, these pieces of evidence begin to stack up in a manner which make a much stronger case for the necessity to carefully review both our acceptance of the efficient market theory and our methodological procedures."

The existence and persistence of these anomalies has been one of the main issues contributing to the emergence of behavioral finance. They led researchers to suspect that the investors may not be as rational as the efficient markets aficionados claimed, or that markets do not behave as if all investors are rational, and hence that studies probing the behavior of decision makers without assuming they are perfectly rational are needed.

\section{Market Efficiency/Inefficiency Findings Critique}

$>$ The joint hypothesis issue

$>$ Insufficient data

$>$ Anomalies could be temporary

Market efficiency tests and or market inefficiency findings could be flawed because of the following reasons, and both proponents and opponents of the EMH used them one against the other. 
- The joint hypothesis issue: When measuring normal returns, we assume a pricing model, so when testing the anomaly, we test both the theory and that the profits are above those implied by the theory. For example, if we use the CAPM as our theory (pricing model), deviations from the normal profits prescribed by the CAPM could stem either from inefficiency or from the fact that the CAPM is not the correct theory. Hence, one cannot be sure which of these factors is responsible for these deviations.

- Insufficient data: For reliable inference, a long history of prices is needed and such data are not always available.

- Anomalies could be temporary: Above-normal profits may emerge, disappear and reemerge.

There also exist the more general methodological questions, which are true for all research and also for both sides of the efficient markets debate, and these are the issues of data snooping, data mining and of the $5 \%$ significance rule. Authors tend to focus on "surprising" or "interesting" results since these are easier to publish. Authors also like to publish evidence for their theories rather than against them. These authors may look at the same or similar data as those preceding them finding corroborating evidence for the initial "surprising" or "interesting" results, although really they did not find anything new. In the same vein, because of the prevalent use of the $5 \%$ significance level requirement, which is the common yardstick according to which researchers deem their results significant or not, $5 \%$ of regressions could be found significant even if based on nothing. Researchers usually just report successes (tests that are significant), but do not disclose information on all the experiments that they conducted. It is hence possible that some of the significant results reported in the literature, and maybe some of the reported anomalies, are just the product of this type of practice.

However, the defense against opponents of market efficiency based on statistical and data issues became increasingly harder over time as the evidence against this hypothesis piled up. Instead, other researchers suggested that the markets were efficient, but that the inefficiency findings were due to the use of inappropriate pricing theories, and that these theories should be revised. 


\section{Extensions of the CAPM and Multi Factor Asset Pricing Theories}

\section{$>$ The APT \\ $>$ Fama-French multi-factor asset pricing model \\ $>$ Fama-French five factor asset pricing model}

As previously noted, findings of abnormal profits could be attributed to market inefficiency, but they could also be spurious and due to misspecification of the theory. Since it was found that the CAPM could not explain prices and that above-normal profits according to this model could be made, some researchers concluded that the CAPM could be insufficient, and that there are more sources of risk in addition to the firm's beta that should be considered. New theories were hence proposed to replace it. Some theorists suggested to look at consumption betas rather than market betas (see, e.g., Breeden et al., 1989), and others (see, e.g., Levy, 1980) suggested extensions of the CAPM, generalized CAPM (or GCAPM), taking into consideration limits on the number of assets in investors' portfolios.

$$
\begin{gathered}
\text { The Arbitrage Pricing Theory } \\
E\left[R_{i}\right]=R_{f}+\gamma_{1 i} F_{1}+\gamma_{2 i} F_{2}+\cdots+\gamma_{n i} F_{n}
\end{gathered}
$$

One of the more influential and compelling theories was the Arbitrage Pricing Theory (APT), proposed by Ross (1976) and Roll and Ross (1980). This theory posits that there exist some non-diversifiable factors $F_{1}, \ldots, F_{n}$ that determine firm's returns. Firm $i$ 's expected returns are hence given by

$$
E\left[R_{i}\right]=R_{f}+\gamma_{1 i} F_{1}+\gamma_{2 i} F_{2}+\cdots+\gamma_{n i} F_{n}
$$

where $\gamma_{1 i}$ is firm $i$ 's sensitivity to factor $1, \gamma_{2 i}$ is firm $i$ 's sensitivity to the second factor and so on to factor $n$. We note that the CAPM is a special case of the APT where $F_{1}$ is $\left[E\left(R_{m}\right)-R_{f}\right]$ and $\gamma_{1 i}=\beta_{i}$. Roll and Ross suggested factor analysis methods to find these factors. 


\section{Fama French Four Factor Asset Pricing Model}

$$
E\left[R_{i}\right]=R_{f}+\gamma_{1 i} F_{1}+\gamma_{2 i} F_{2}+\cdots+\gamma_{4 i} F_{4}
$$

where

$F_{1}$ : Returns on the market,

$F_{2}$ : SMB: Relative returns of "small" firms vs. "large" firms (Small Minus Big),

$F_{3}$ : HML: Relative returns of high vs. low book to market firms (High Minus Low),

$F_{4}$ : MOM: The extra returns earned by high momentum firms relative to low momentum firms.

Although the APT presented an improvement over the CAPM, it was hard to apply and inaccessible to the layperson because the factors were somewhat abstract. Fama and French $(1992,1993)$ simplified this model by replacing the abstract factors by more concrete ones and by making these factors available to all, free of charge, in Prof. Ken French's website. They introduced a four-factor pricing model, which is similar to the original APT, but with the following definition of the factors explaining the returns of the individual firms:

The size portfolio return/factor (SMB) is approximated by the difference in monthly returns on the small cap index and the large cap index. The book-to-market factor (HML) is approximated by the return difference between high value portfolios and growth portfolios. The momentum factor (MOM) is the difference in monthly returns between a group of stocks with recent above-average returns and another group of stocks with recent below-average returns.

The group with above-average returns is defined as, say, the top $30 \%$ of stocks from the S\&P index over the past 11 months and the below-average group contains the lowest $30 \%$ of stocks from the same index over the same time period. Professor Ken French maintains these factors in his website: http://mba.tuck.dartmouth.edu/ pages/faculty/ken.french/. A more detailed description of the above variables can be obtained from this website. 


\section{Fama French Five Factor Asset Pricing Model}

As the four factors model could not explain all inefficiencies, the exploration for new factors continued. In 2014, Fama and French introduced a new model with two additional factors:

RMW: a profitability factor, Robust Minus Weak, CMA: an investment factor, Conservative Minus Aggressive.

The new five factor model is now given by the following equation:

$$
\begin{aligned}
R_{i t}-R_{F t}= & \alpha_{i}+\beta_{i}\left(R_{M t}-R_{F t}\right)+\sigma_{i} \mathrm{SMB}_{t}+\eta_{i} \mathrm{HML}_{t} \\
& +\rho_{i} \mathrm{RMW}_{t}+\chi_{i} \mathrm{CMAt}+\varepsilon_{i t}
\end{aligned}
$$

This model is similar to the four-factor model, except that the MOM factor has been removed and that two new factors were introduced: RMW and CMA. For full details, see Fama and French (2014).

While we concentrated above on financial economists' attempts to explain the behavior of capital markets by rationality and efficient markets, in the next lecture, we will discuss the progress psychologists made in looking for and finding examples of individuals behaving irrationally and providing theories to explain such behavior.

\section{Conclusion}

> Behavioral finance was described.

$>$ Market efficiency, arbitrage, the CAPM and more advanced pricing theories were reviewed.

> Early period (1970s and 1980s) anomalies were reviewed.

> The vacuum in finance theory that behavioral finance was meant to fill and the impetus for its rise were explained. 